\title{
A Migração de Haitianos para o Brasil
}

\author{
Mariana Longhi Batista Alessi ${ }^{1}$
}

\section{RESUMO}

Desde o terremoto de janeiro de 2010, uma onda de haitianos passou a buscar refúgio no território brasileiro. O presente artigo visa comentar, brevemente, como o governo brasileiro vem lidando com a vinda dos haitianos.

Palavras-chave: Brasil; Haitianos; Migração.

Em 30 de abril de 2004, o Conselho de Segurança da ONU criou a MINUSTAH (Missão das Nações Unidas para a estabilização do Haiti), por meio da resolução 1542, para restaurar a ordem no país após um período de crise política que culminou com a deposição do então presidente Jean-Bertrand Aristide. O Brasil foi apontado pela ONU como líder dessa missão com objetivos pacificadores no Haiti.

Desde o início da missão, o Haiti já recebeu cerca de 15.000 militares brasileiros. Em 12 de janeiro de 2010, cerca de 1.200 militares brasileiros atuavam no país quando um terremoto de, aproximadamente, 5.9 graus na escala Richter devastou a capital Porto Príncipe e outras regiões no país. Se tivesse ocorrido no Japão, esse terremoto teria sido apenas mais um e raros seriam os estragos físicos na rica nação. Como ocorreu no país mais pobre das Américas, o terremoto devastou a já paupérrima região da capital Porto Príncipe. Os números oficiais de mortos no terremoto são 230.000 (duzentos e trinta mil), porém, estima-se que esse número tenha chegado a 240.000 (duzentos e quarenta mil).

Os oficiais do exército brasileiro na MINUSTAH, que há muito trabalhavam no país, intensificaram ainda mais as relações e trabalhos após a tragédia. Inúmeros são os relatos de cidadãos haitianos que aprenderam o português e se aproximaram dos brasileiros durante todo esse período. 0 que pode ser percebido em relatos jornalísticos

\footnotetext{
${ }^{1}$ Mariana Longhi Batista Alessi é graduada em Relações Internacionais, especialista em Negócios Internacionais, mestranda do programa de pós-graduação em Ciência Política da UFPR e pesquisadora do Núcleo de Estudos e Pesquisas em Relações Internacionais (NEPRI).
} 
é que este intenso convívio despertou o interesse e simpatia do povo haitiano, que tem visto no Brasil não somente um sinônimo de ajuda, mas sim de oportunidade.

É válido lembrar que o Brasil tem estado em evidência nos últimos anos. A Copa do Mundo de 2014, as Olimpíadas de 2016 e diversas oportunidades de desenvolvimento com grandes empresas multinacionais se transferindo pra cá, agregando o fator da proximidade com os militares brasileiros no Haiti, fizeram do Brasil um destino atraente para o refúgio dos haitianos. Estima-se que desde o terremoto de 2010 até Maio de 2013, entraram no país ilegalmente cerca de 9.000 haitianos ${ }^{2}$. A viagem ilegal até o Brasil é longa, de alto custo e feita em condições subhumanas. O trajeto vai desde a Republica Dominicana, passando por países como Equador e Peru, chegando aos estados do Amazonas e do Acre.

Ante esta nova realidade, é válido observar uma questão que, todavia, não foi respondida: seriam os motivos acima descritos como possíveis responsáveis pela vinda dos haitianos a buscar novas oportunidades no nosso país? Esgotadas as esperanças de uma vida melhor, seria a escolha do Brasil uma consequência das relações desenvolvidas durante a MINUSTAH?

O governo brasileiro vem, muito lentamente, estudando e reagindo a esta nova realidade. Primeiramente, os haitianos solicitaram ao Conselho Nacional para Refugiados (CONARE) o pedido de refúgio político. Entretanto, em 2012, esse conselho atribuiu à situação destes como imigrantes oriundos de situações humanitárias.

Para dar conta dos fatos dessa migração ilegal, o governo brasileiro vem trabalhando no sentido de normatizar essa situação. Foi publicado no Diário Oficial da União, em 13 de janeiro de 2012, a resolução normativa número 97 do Conselho Nacional de Imigração sobre a concessão de vistos permanentes a cidadãos haitianos. A Resolução Normativa prevê que, ao nacional do Haiti, poderá ser concedido o visto permanente por razões humanitárias, condicionado ao prazo de 5 anos. Como parágrafo único da resolução, ficou caracterizado, como razões humanitárias, aquelas resultantes do agravamento das condições de vida da população haitiana, em decorrência do terremoto ocorrido naquele país em 12 de janeiro de 2010. Os vistos disciplinados por esta Resolução Normativa serão concedidos pelo Ministério das Relações Exteriores, por intermédio da Embaixada do Brasil em Porto Príncipe, e serão concedidos a uma média

\footnotetext{
2 Dados estimados do Conselho Nacional de Imigração.
} 
de 100 (cem) concessões por mês e até 1.200 (mil e duzentos) por ano, sem a prévia necessidade de contrato de trabalho estabelecido no Brasil.

Em coletiva publicada pelo Ministério das Relações Exteriores ${ }^{3}$, o Presidente do CONARE, Luiz Paulo Barreto, esclareceu que vistos concedidos a um cidadão com condições de trabalho compreendem a possibilidade de abertura para a vinda de toda família, o que aumentaria esse número para 100 famílias. O Ministro das Relações, Exteriores Antonio Patriota, declarou que a determinação da quantidade de vistos foi feita com base em anos anteriores e ele acreditava que essa soma seria mais que suficiente. Porém, anos anteriores não refletem a realidade atual, ademais, seguia aberta, então, a situação dos atuais 4.000 haitianos, que já se encontravam em território nacional e que não se encaixam no perfil de refugiados.

Recentemente, em 15 de Maio de 2013, o Ministério das Relações Exteriores divulgou nota sobre a migração de cidadãos haitianos para a América do Sul, dizendo ser possível comprovar a atuação de redes criminosas no tráfico de migrantes neste roteiro. Nesse sentido, o governo brasileiro decidiu ampliar ainda mais a concessão de vistos permanentes especiais para nacionais haitianos, como forma de valorizar a imigração legal e segura e combater o tráfico de imigrantes. Autoridades da Bolívia, Colômbia, Equador, Haiti, Peru e República Dominicana participaram de uma Reunião de Coordenação Regional sobre a Migração de Cidadãos Haitianos para a América do Sul em Brasília e se comprometeram a intensificar as fiscalizações e atuação neste sentido ${ }^{4}$.

É muito cedo ainda para que se possa afirmar sobre os reais motivos da escolha do Brasil pelos haitianos que conseguiram escapar da realidade degradante na qual o país se encontra. 0 que se sabe é que, apesar das resoluções normativas e uma tentativa (mesmo que inicial) do governo de acolher os haitianos, todavia, não existe estrutura física ou preparação dos órgãos governamentais (tais como a Polícia Federal ou o Conselho Nacional de Imigração) para essa acolhida. Os haitianos que já estão aqui, após milhares de quilômetros de sofrimento e angústia, sofrem agora com os entraves burocráticos para a documentação legal e a chance de viver dignamente.

\footnotetext{
${ }^{3}$ Disponível em http://www.itamaraty.gov.br

4 Disponível em http://www.itamaraty.gov.br/sala-de-imprensa/notas-a-imprensa/reuniao-de-coordenacaoregional-sobre-a-migracao-de-cidadaos-haitianos-para-a-america-do-sul
} 
A situação, descrita sucintamente, indica a importância da construção de uma perspectiva sobre a atual situação dos haitianos no Brasil. É importante salientar que a crise haitiana e seu inevitável fluxo migratório possuem um significado que vai além de suas fronteiras e que pode servir de lição de como enfrentar futuras situações similares.

É necessário que o Governo Brasileiro e seus órgãos reguladores ofereçam a devida importância à situação em que esses seres humanos se encontram, buscando atuar de maneira mais prática a regularizar essa situação. Haitianos e cidadãos oriundos de outras nacionalidades encontram-se jogados em abrigos, casas de apoio, regiões de fronteiras ou até mesmo sendo explorados por brasileiros sem escrúpulos que se aproveitam da vulnerabilidade em que se encontram, que é agravada ainda mais por entraves burocráticos e falta de estrutura. A situação já ocorre há mais de três anos e está na hora de proporcionar uma resposta mais prática e menos teórica. Empregadores em busca de mão de obra, já faltante em nosso país, e que gostariam de contratar essas pessoas, concordam que o Governo poderia mediar e contribuir, facilitando a regularização da documentação. Uma grande chance que certamente os haitianos que aqui estão não querem deixar passar.

\section{Referências Bibliográficas}

BERTINO, Julia Moreira. Política em relação aos refugiados no Brasil (1947 - 2010). UNICAMP, Campinas, 2012 (tese de Doutorado)

GRATIUS, Susanne. O Brasil nas Américas: Potência regional Pacificadora? Disponível em <http://www.fride.org/publicacion/223/brasil-en-las-americas-una-potenciaregional-pacificadora>. Acessado em: 11.out.2012.

FERRACIOLI, Luara. Morality in Migration: Duties of Inclusion and Exclusion. Australian National University, 2011 (tese de Doutorado).

ROCHA, Antonio Jorge Ramalho da. Missões de Paz em Estados Frágeis: Elementos para se Refletir sobre a Presença do Brasil no Haiti . In: NASSER, Reginaldo Mattar (Org.). Os Conflitos Internacionais em Múltiplas Dimensões. São Paulo: UNESP, 2009. 
SEITENFUS, Ricardo. Elementos para uma Diplomacia Solidária: a Crise Haitiana e os Desafios da Ordem Internacional Contemporânea. Disponível em <http://www.brasilhaiti.com/conteudoartigos.asp?ID=2>. Acessado em 09.abr.2013.

SEITENFUS, Ricardo. Do Suez ao Haiti: a participação brasileira nas Operações de Paz. Disponível em <http://www.brasilhaiti.com/conteudoartigos.asp?ID=2>. Acessado em 15.nov.2012.

TELEMAQUE, Jenny. Imigração Haitiana na mídia brasileira. Disponível em <http://www.brasilhaiti.com/conteudoartigos.asp?ID=2>. Acessado em 09.abr.2013.

UZIEL, Eduardo. Três Questões Empíricas, uma Teórica e a Participação do Brasil em Operações de Paz das Nações Unidas. In: Política Externa. Vol. 14, n 4, 2006.

USHIJIMA, Fernanda R. A Política Externa Brasileira para os emigrantes e seus descendentes. São Paulo: Cultura Acadêmica, 2012.

VALLER FILHO, Wladimir. O Brasil e a Crise Haitiana: a cooperação técnica como instrumento de solidariedade e de ação diplomática. Brasília: FUNAG, 2007.

\section{Sítios Eletrônicos}

http://haiti.org.br/

http://www.brasilhaiti.com/

http://www.foreignpolicy.com/articles

http://www.itamaraty.gov.br 